\title{
The Effect of Dexmedetomidine on Oxygenation and Intrapulmonary Shunt during One Lung Ventilation
}

\author{
Mehmet I. Buget'1, Zerrin Sungur', Berker Ozkan², Mesut Yornuk', \\ Fatma Demircan', Mert Senturk ${ }^{1}$ \\ ${ }^{1}$ Department of Anaesthesiology, Istanbul Medical Faculty, Istanbul University, Istanbul, Turkey \\ ${ }^{2}$ Department of Thoracic Surgery, Istanbul Medical Faculty, Istanbul University, Istanbul, Turkey \\ Email: mbuget@yahoo.com
}

Received 20 June 2015; accepted 12 July 2015; published 15 July 2015

Copyright (C) 2015 by authors and Scientific Research Publishing Inc.

This work is licensed under the Creative Commons Attribution International License (CC BY).

http://creativecommons.org/licenses/by/4.0/

(c) (i) 0pen Access

\begin{abstract}
Background: The effect of intravenously administered dexmedetomidine on oxygenation during one-lung ventilation has not been studied. The hypothesis of this prospective, randomized study was that dexmedetomidine would be associated with an improvement in oxygenation during onelung ventilation. The secondary outcome was the change in the intrapulmonary shunt. Materials and Methods: Thirty patients undergoing one-lung ventilation were included. Patients in Group D ( $n=15$ ) received a bolus dose of $1 \mu \mathrm{g} \cdot \mathrm{kg}^{-1}$ dexmedetomidine at $10 \mathrm{~min}$ after induction of anaesthesia followed by an infusion of $0.4 \mu \mathrm{g} \cdot \mathrm{kg}^{-1} \cdot \mathrm{hr}^{-1}$ that was stopped at the end of the surgery, and those in the control group (Group $\mathrm{C}, \mathrm{n}=15$ ) were given saline at the same dosage. Vital signs, $\mathrm{PaO}_{2}$, and pulmonary shunting (Qs/Qt) were compared. Results: During one-lung ventilation, the $\mathrm{PaO}_{2}$ in Group D increased significantly and Qs/Qt significantly decreased compared to Group $\mathrm{C} \mathrm{PaO}_{2}$, $203.7 \pm 42.3 \mathrm{mmHg}$ vs. $173 \pm 37.6 \mathrm{mmHg}[\mathrm{P}=0.04]$ and $\mathrm{Qs} / \mathrm{Qt} 19.8 \% \pm 4.5 \%$ vs. $31 \% \pm 2.4 \%[\mathrm{P}<$ 0.0001], Group D and Group C, respectively). Conclusion: Intravenous administration of dexmedetomidine achieved an improvement in oxygenation during one-lung ventilation. This was associated with a decrease in pulmonary shunt. Use of intraoperative dexmedetomidine during thoracic surgery can be suggested.
\end{abstract}

\section{Keywords}

Dexmedetomidine, One-Lung Ventilation, Intrapulmonary Shunt

\section{Introduction}

During thoracic anaesthesia, one-lung ventilation (OLV) is associated with an increase in pulmonary shunt as a

How to cite this paper: Buget, M.I., Sungur, Z., Ozkan, B., Yornuk, M., Demircan, F. and Senturk, M. (2015) The Effect of Dexmedetomidine on Oxygenation and Intrapulmonary Shunt during One Lung Ventilation. Open Journal of Anesthesiology, 5, 135-141. http://dx.doi.org/10.4236/ojanes.2015.57025 
result of persisting perfusion of the non-ventilated lung [1]. This increase, along with other factors, leads to hypoxemia in approximately $5 \%-10 \%$ of patients. Therefore, prevention and treatment of hypoxemia during OLV is crucial [2]. While the potential effects of a number of drugs on oxygenation during OLV have been studied during previous decades, the effects of more recent drugs remain to be examined [3].

Dexmedetomidine is a highly selective $\alpha_{2}$-adrenoceptor agonist. It is a widely used anaesthetic adjunct, and there has been a growing interest in its use in different patient populations, regional anaesthesia, critical care, and thoracic surgery [4]-[6]. Dexmedetomidine has all of the features of clonidine but has not been associated with respiratory depression, which can make it a beneficial supplement in the clinical setting [7] [8]. The effects of clonidine on oxygenation during OLV [9], as well as the effects of epidural dexmedetomidine administration on intraoperative awareness and post-op pain after OLV [6], have been examined in previous studies. Regarding the effect of intravenously administered dexmedetomidine on oxygenation during OLV, there is only one study with lower doses showing that there is no significant change in $\mathrm{PaO}_{2}$ [10].

It has been shown that clonidine reduces the intrapulmonary shunt and improves oxygenation [9]. Therefore, the hypothesis of this prospective, randomized study was that dexmedetomidine would be associated with an improvement in oxygenation during one-lung ventilation. The secondary outcome was the change in the intrapulmonary shunt.

\section{Materials and Methods}

After obtaining approval of Istanbul Medical Faculty Ethical Committee (protocol no: 200560-09/03/2005) and written and informed patient consent, 30 American Society of Anaesthesiologists (ASA) physical status I-III patients, 18 - 65 years of age, who were undergoing elective thoracotomy were enrolled in this randomized double-blind clinical study with an allocation ratio of 1:1. We made power analysis for justification of sample size. To detect a change of $40 \mathrm{mmHg}$ in $\mathrm{PaO}_{2}$ (accepting an alpha error of $5 \%$ and a beta error of $20 \%$ ), the required study size was 13 patients per group. Our study was conducted in year 2005 for a 6 month period. Patients with bradycardia, serious heart block, uncontrolled hyper- or hypotension, and failure of organs other than the lungs (renal, hepatic vs.) were excluded from the study. After randomization, the application of any additional drug or manoeuvre (e.g. vasopressors to maintain hemodynamic stability) that could cause any bias, was considered a perioperative exclusion criteria.

No patient received premedication. Before induction of anaesthesia, all patients were hydrated with $200 \mathrm{~mL}$ of saline. ECG, $\mathrm{SpO}_{2}$, temperature, end tidal carbon dioxide, invasive arterial blood pressure (ABP) (Primus Dräger, Lübeck, Germany), core temperature, and bispectral index (BIS) (Aspect Medical System, Newton, MA, USA) were monitored in all patients.

A thoracic epidural catheter was inserted prior to induction by a midline approach using the "loss of resistance" technique and was not used during the intraoperative period.

For the anaesthesia induction, after administration of fentanyl $2 \mu \mathrm{g} \cdot \mathrm{kg}^{-1}$, propofol was titrated in each patient until (BIS) values were below 50 and $0.1 \mathrm{mg} \cdot \mathrm{kg}^{-1}$ vecuronium was used for muscle relaxation. A double lumen tube, 35 - 37 French (F) for female patients and 39 - $41 \mathrm{~F}$ for male patients (Mallinckrodt, Athlone, Ireland) was used forendotracheal intubation; left bronchial double lumen tubes were used unless there was contraindication. Optimal placement of the tubes was confirmed with fiberoptic bronchoscopy in every case. A multilumen central venous catheter was placed via the v. subclavia of the operative side and central venous pressure was monitored. We used $40 \% \mathrm{O}_{2}$-air mixtures before and after $\mathrm{OLV}$ and $80 \% \mathrm{O}_{2}$-air mixtures during OLV. Maintenance of anaesthesia was established with a propofol infusion titrated to BIS level 40 - 60, and incremental doses of fentanyl were administered according to clinical findings. Pressure-controlled ventilation was used throughout the entire surgery; the driving pressure of ventilation was set to supply a tidal volume that maintainednormocapnia (end-tidal $\mathrm{CO}_{2}$ values of 30 - $35 \mathrm{mmHg}$; Primus Dräger, Lübeck, Germany). The pressure was reset during OLV. PEEP $\left(4 \mathrm{~cm} \mathrm{H}_{2} \mathrm{O}\right)$ was applied throughout the mechanical ventilation to all patients; frequency was $11 / \mathrm{min}$ with an I:E ratio of 1:2.

In Group D ( $\mathrm{n}=15)$, a bolus dose of $1 \mu \mathrm{g} \cdot \mathrm{kg}^{-1}$ dexmedetomidine (Precedex, Hospira, Inc. Lake Forest, USA) was given at 10 min following anaesthesia induction, after which the dexmedetomidine infusion was maintained at a dose of $0.4 \mu \mathrm{g} \cdot \mathrm{kg}^{-1} \cdot \mathrm{hr}^{-1}$. The infusion was stopped at the end of the surgery. In the control group, Group C(n $=15$ ), after the same anaesthesia induction, the same amount of saline, instead of dexmedetomidine, was infused by the same protocol. All infusions were randomly prepared by a doctor who did not participate in the study, 
placed in non-labelled infusion pumps, and given to the anaesthesiologist, who was blinded to the content of the infusion. Randomisation was performed via a sealed envelope technique. Infusions in both groups were stopped prior to skin closure.

In both groups, arterial and central venous samples were obtained at three time points: T1, 10 minutes after the anaesthesia induction and before OLV; T2, 10 minutes after initiation of OLV; and T3, 20 minutes after cessation of OLV. The heart rate, mean arterial pressure, arterial oxygen pressure $\left(\mathrm{paO}_{2}\right)$ and arterial carbon dioxide pressure $\left(\mathrm{paCO}_{2}\right)$, central venous pressure, haemoglobin, central venous oxygen saturation $\left(\mathrm{SvO}_{2}\right)$, central venous oxygen $\left(\mathrm{pvO}_{2}\right)$, and venous carbon dioxide $\left(\mathrm{pvCO}_{2}\right)$ pressures were recorded, and Qs/Qt values were calculated for each measurement time.

Right atrial blood was used to calculate Qs/Qt instead of the pulmonary arterial blood. This is a method which has been preferred by many authors [11]-[13]. Qs/Qt was calculated from the formula below, with respiratory quotient $(\mathrm{RQ})=0.8$ and $\mathrm{SaO}_{2}=$ arterial oxygen saturation.

$$
\begin{aligned}
& \mathrm{CaO}_{2}=\left(\mathrm{PaO}_{2} \times 0.0031\right)+\left(\mathrm{Hb} \times 1.36 \times \mathrm{SaO}_{2}\right) \\
& \mathrm{CvO}_{2}=\left(\mathrm{PvO}_{2} \times 0.0031\right)+\left(\mathrm{Hb} \times 1.36 \times \mathrm{SvO}_{2}\right) \\
& \mathrm{CcO}_{2}=\left(\left[\mathrm{FiO}_{2} \times\left(\mathrm{P}_{\mathrm{B}}-\mathrm{P}_{\mathrm{H}_{2} \mathrm{O}}\right)-\mathrm{PaCO}_{2} / \mathrm{RQ}\right] \times 0.0031\right)+(\mathrm{Hb} \times 1.36) \\
& \mathrm{Qs} / \mathrm{Qt}=\left(\mathrm{CcO}_{2}-\mathrm{CaO}_{2}\right) /\left(\mathrm{CcO}_{2}-\mathrm{CvO}_{2}\right)
\end{aligned}
$$

All patients were extubated at the end of the operation and a mixture of bupivacaine and morphine was used administered for postoperative analgesia via patient controlled epidural analgesia (PCEA).

\section{Statistical Analyses}

Statistical analysis was performed using Graph PadInstat (GraphPad Software, San Diego, CA, USA). The normality of distribution was tested by Kolmogorov-Smirnov test. Comparisons between the groups at the same measurement times were performed with Student's t-test. Data within a group at different measurement times were compared with repeated measures ANOVA (except oxygenation parameters, because the $\mathrm{FiO}_{2}$ was varied between measurement times) Student's t-test and independent samples t-test were used for group comparisons. For all analyses, a P-value of $<0.05$ value was accepted as significant.

\section{Results}

No patient was excluded after randomization. There were no differences between Groups in terms of patient

\begin{tabular}{|c|c|c|c|}
\hline & Group D Dexmedetomidine group $(\mathrm{n}=15)$ & Group C Control group $(\mathrm{n}=15)$ & P-value \\
\hline \multicolumn{4}{|l|}{ Demographic data } \\
\hline Gender male/female & $11 / 4$ & $10 / 5$ & \\
\hline Age (years) & $55.25 \pm 15.8$ & $52.33 \pm 10.7$ & 0.68 \\
\hline Weight (kg) & $74.33 \pm 13.29$ & $69.16 \pm 7.5$ & 0.38 \\
\hline \multicolumn{4}{|l|}{ Perioperative data } \\
\hline \multicolumn{4}{|l|}{ Operation type } \\
\hline lobectomy & $11(73.33 \%)$ & $9(60 \%)$ & \\
\hline pneumonectomy & $2(13.33 \%)$ & $3(20 \%)$ & \\
\hline hydatid cyst & $1(6.6 \%)$ & $1(6.6 \%)$ & \\
\hline bullectomy & & $1(6.6 \%)$ & \\
\hline diaphragm repair & $1(6.6 \%)$ & $1(6.6 \%)$ & \\
\hline Operation time (min) & $161.2 \pm 38.6$ & $132.5 \pm 50.5$ & 0.17 \\
\hline OLV time (min) & $69 \pm 28.5$ & $73 \pm 30$ & 0.71 \\
\hline
\end{tabular}
characteristics, operative times, and duration of OLV (Table 1). Demographic data values were statistically insignificant $(\mathrm{P}<0.05)$.

\section{Table 1. Patient characteristics and perioperative data.}

Data are as mean \pm standard deviation. 
There were also no differences between groups in any parameter among the pre-OLV measurements (Table 2). During OLV, there were no differences in heart rate, mean arterial pressure, and oxygenation parameters between groups, but there were significant differences in oxygenation $\left(\mathrm{PaO}_{2}=203.7 \pm 42.3 \mathrm{mmHg}\right.$ Group $\mathrm{D}$ and $173.0 \pm 37.6 \mathrm{mmHg}$ Group $\mathrm{C}, \mathrm{P}=0.004)$ and shunt values $(\mathrm{Qs} / \mathrm{Qt}=19.8 \% \pm 4.5$, Group D and $31.0 \% \pm 2.4$ Group C, P $<0.0001$ ) (Table 3).

After one lung ventilation, there were again no statistically significant differences between the groups (Table 4). Heart rate, mean arterial pressure, arterial oxygen, venous oxygen saturation, venous oxygen and shunt values did not showed any differences after OLV.

There were no differences between the two groups in any of the measured $\mathrm{PvO}_{2}$ values. There was a decrease in propofol requirement among the patients in Group D vs. those in the control group withamean propofol infusion value of $9.2 \pm 1.9 \mathrm{mg} \cdot \mathrm{kg}^{-1} \cdot \mathrm{h}^{-1}$, Group D, vs. $6.5 \pm 1.8 \mathrm{mg} \cdot \mathrm{kg}^{-1} \cdot \mathrm{h}^{-1}$, Group C $(\mathrm{P}=0.0004)$.

Table 2. Oxygenation parameters Before OLV.

\begin{tabular}{cccc}
\hline & Group D & Group C & P-value \\
\hline $\mathrm{HR}$ (beat/min) & $66.6 \pm 15.1$ & $68.2 \pm 10.5$ & 0.84 \\
$\mathrm{MAP}(\mathrm{mmHg})$ & $83.21 \pm 12.54$ & $84.85 \pm 19.82$ & 0.23 \\
$\mathrm{PaO}_{2}(\mathrm{mmHg})$ & $213.2 \pm 46.36$ & $201.4 \pm 25.8$ & 0.39 \\
$\mathrm{SvO}_{2}(\%)$ & $71.27 \pm 12.45$ & $77.1 \pm 12.4$ & 0.20 \\
$\mathrm{PvO}_{2}(\mathrm{mmHg})$ & $43.0 \pm 7.8$ & $48.1 \pm 8.4$ & 0.09 \\
$\mathrm{Qs} / \mathrm{Qt}$ & $12.31 \pm 5.26$ & $15.36 \pm 4.3$ & 0.09 \\
\hline
\end{tabular}

Data are as mean \pm standard deviation. Group D: dexmedetomidine group, Group C: control group, HR: heart rate MAP: Mean arterial pressure, PaO ${ }_{2}$ : arterial oxygen, $\mathrm{SvO}_{2}$ : venous oxygen saturation, $\mathrm{PvO}_{2}$ : venous oxygen, Qs/Qt: shunt.

Table 3. Oxygenation parameters During OLV.

\begin{tabular}{cccc}
\hline & Group D & Group C & P-value \\
HR (beat/min) & $67.7 \pm 16.1$ & $69.2 \pm 13.5$ & 0.86 \\
$\mathrm{MAP}(\mathrm{mmHg})$ & $81.35 \pm 12.25$ & $85.71 \pm 12.01$ & 0.44 \\
$\mathrm{PaO}_{2}(\mathrm{mmHg})$ & $* 203.7 \pm 42.3$ & $* 173.0 \pm 37.6$ & $75.5 \pm 10.1$ \\
$\mathrm{SvO}_{2}(\%)$ & $74.7 \pm 9.056$ & $48.2 \pm 7.7$ & 0.04 \\
$\mathrm{PvO}_{2}(\mathrm{mmHg})$ & $44.6 \pm 4.2$ & $* 31.0 \pm 2.4$ & 0.12 \\
$\mathrm{Qs} / \mathrm{Qt}$ & $* 19.8 \pm 4.5$ & $* 0.0001$
\end{tabular}

Data are as mean \pm standard deviation. Group D: dexmedetomidine group, Group C: control group, HR: heart rate MAP: Mean arterial pressure, PaO ${ }_{2}$ : arterial oxygen, $\mathrm{SvO}_{2}$ : venous oxygen saturation, $\mathrm{PvO}_{2}$ : venous oxygen, Qs/Qt: shunt.* $\mathrm{P}<0.05$ considered significant.

Table 4. Oxygenation parameters After OLV.

\begin{tabular}{cccc}
\hline & Group D & Group C & P-value \\
\hline $\mathrm{HR}$ (beat/min) & $68.6 \pm 16.3$ & $70.6 \pm 14.1$ & 0.72 \\
$\mathrm{MAP}(\mathrm{mmHg})$ & $82.42 \pm 13.3$ & $86.80 \pm 15.7$ & 0.41 \\
$\mathrm{PaO}_{2}(\mathrm{mmHg})$ & $242.7 \pm 42.7$ & $213.3 \pm 40$ & 0.08 \\
$\mathrm{SvO}_{2}(\%)$ & $70.0 \pm 14.5$ & $78.0 \pm 11$ & 0.09 \\
$\mathrm{PvO}_{2}(\mathrm{mmHg})$ & $43.8 \pm 7.5$ & $51.1 \pm 9.0$ & 0.06 \\
Qs/Qt & $14.9 \pm 6.3$ & $15.2 \pm 2.1$ & 0.86
\end{tabular}

Data are as mean \pm standard deviation. Group D: dexmedetomidine group, Group C: control group, HR: heart rate MAP: Mean arterial pressure, PaO ${ }_{2}$ : arterial oxygen, $\mathrm{SvO}_{2}$ : venous oxygen saturation, $\mathrm{PvO}_{2}$ : venous oxygen and Qs/Qt: shunt. 


\section{Discussion}

To our knowledge, this is the first study examining the effects of dexmedetomidine on oxygenation during OLV with TIVA. We found that a dexmedetomidine infusion started before OLV resulted in improved oxygenation and reduced intrapulmonary shunt.

Besides ventilatory injury, hypoxemia during OLV is still regarded as an important challenge of thoracic anaesthesia. Hypoxic pulmonary vasoconstriction (HPV) is a defence mechanism against hypoxia which decreases the shunt so that there is a smaller decline in oxygen than expected [14]. However, it has been decades since any study has directly examined HPV during OLV [15] as the majority of more recent studies "assume" that changes in oxygenation and pulmonary shunt are due to changes in HPV, and this assumption can lead to scientific bias [16]. The anaesthesia strategy should be tailored to preserve adequate oxygenation during OLV (and not to preserve the HPV). The aim of the present study is primarily to evaluate the effects of dexmedetomidine on oxygenation during OLV. Whether these effects are due to changes in HPV (and their value), can only be speculated.

Dexmedetomidine is effective in postoperative analgesia, reducing postoperative morphine requirements without increasing the incidence of side effects [17]. Its sedative effects have also been well-studied, and its use in paediatric populations, cardiovascular anaesthesia, and regional anaesthesia is increasing. Elhakimand colleagues have reported that the use of epidural dexmedetomidine during OLV resulted in significant decreases in anaesthetic requirement, prevented awareness during anaesthesia, and improved intraoperative oxygenation and post-operative analgesia [6].

In terms of its $\alpha_{2}$-mimetic effects, dexmedetomidine may affect HPV in contrary ways; while it might be expected that dexmedetomidine would impair the HPV response because of pulmonary vasodilation in non-ventilated lung, it is also possible that the vasodilation in the ventilated lung may be dominant, and the results of our study, in which dexmedetomidine has achieved a more appropriate ventilation-perfusion match, support the latter explanation. The findings of a 1968 study by Silove and Grover demonstrated that an $\alpha$-adrenergic blockade abolished the pulmonary vasoconstrictor responding to noradrenaline but not to hypoxia [18]. That is, hypoxiainduced pulmonary vasoconstriction cannot be impaired by sympathetic blockade. This suggests that the sympatholytic effects of dexmedetomidine would increase the ratio of blood flow to vasodilated areas of ventilated lung.

The results of a study examining the effects of clonidine on oxygenation and Qs/Qt by Lübbeand colleagues were similar results of the present study [9]. They demonstrated in 20 dogs that clonidine decreased Qs/Qt (consecutively $18.3 \% \pm 5.5 \%$ and $26.6 \% \pm 5.5 \%$ ) and improved $\mathrm{PaO}_{2}$ (consecutively $390 \pm 99 \mathrm{mmHg}$ and $323 \pm 94$ $\mathrm{mmHg}$ ) during OLV when compared with controls. They also suggested that the decreased sympathetic toneafter clonidine administration could cause these changes. Dexmedetomidine is a more selective $\alpha_{2}$-agonist than clonidine, and we also found that oxygenation was improved and Qs/Qt values were reduced in patients receiving dexmedetomidine, compared with the controls, during OLV. Shunt values before OLV and after OLV were not affected. That the effects were limited to a period of differentiated blood flow also support this explanation.

In a study by Kernanand associates, dexmedetomidine during OLV did not cause a significant change in oxygenation $\left(\mathrm{PaO}_{2} / \mathrm{FiO}_{2}\right.$ ratio of $188 \pm 115$ in dexmedetomidine patients versus $135 \pm 70 \mathrm{mmHg}$ in placebo patients) [10]. They used desflurane for the maintenance of anaesthesia, and they speculated that the slight (albeit insignificant) improvement in oxygenation with dexmedetomidine might have resulted from the anaesthetic-sparing effect of dexmedetomidine, thereby allowing for a decrease in the concentration of desflurane and a subsequent lessening of its effects on HPV. However, there are two important drawbacks. First, it is known that desflurane inhibits HPV, if at all, in a very limited ratio [19]. Furthermore, the study was a cross-over study in which thepatients served as their own controls. Thus, it could not be assured that dexmedetomidine had been fully washedout in cases where it was used first. Our study, on the other hand, was designed as a controlled two-group study and propofol which is known as having no effects on HPV [20], was used for the maintenance of anaesthesia. Not at least, that study was performed with very lower bolus dose $\left(0.3 \mu \mathrm{g} \cdot \mathrm{kg}^{-1}\right)$ and infusion rate $\left(0.3 \mu \mathrm{g} \cdot \mathrm{kg}^{-1} \cdot \mathrm{hr}^{-1}\right)$ compared with the present one; which can be another explanation for that the increase in $\mathrm{PaO}_{2}$ was not significant.

As our study was a clinical trial, it did not allow for a comprehensive examination of the pathway of changes to HPV and oxygenation associated with dexmedetomidine, but possibilities other than sympathetic blockade may exist. First, dexmedetomidine decreases intravenous anaesthetic requirements significantly. In one study 
[21], propofol requirements were reduced by $30 \%$, and a similar reduction was observed in our study. However, in our study, the dexmedetomidine infusion was started after induction, and this made it inappropriate to offer a precise judgment for anaesthesia consumption levels. Numerous studies have shown that propofol does not affect intrapulmonary shunt [20]. Therefore, in our study, the reduced intrapulmonary shunt in the dexmedetomidine group cannot be attributed to the reduced propofol consumption.

Second, $\alpha_{2}$-agonists affect oxygen consumption at the tissue level and they are associated with changes in the arterio-venous difference of oxygen content $\left(\mathrm{avDO}_{2}\right)$ [22]. Changes in mixed venous $\mathrm{O}_{2}$ can lead to changes in HPV. However, there were no differences in central venous oxygen pressure between the groups in our study; therefore, this appears also not to be an explanation of the results. We used the $\mathrm{PvCO}_{2}$ instead of mixed venous oxygen pressure, but whether this was a cause of some degree of bias will have to be answered in future studies.

As a third possibility, it has been demonstrated an animal model that dexmedetomidine may also lead to transient increases in pulmonary artery pressure related to its direct effects on vascular smooth muscle through $\alpha$-adrenergic receptors [23]. This paradoxical effect may also cause a potentiation of HPV. Once again, however, it is not possible to prove this assumption in the clinical setting, nor is it the aim of our study.

Alpha-2 agonists have dose-dependent effect on circulating catecholamine, and the effect of dexmedetomidine effect is more apparent than that of clonidine, in that dexmedetomidine can reduce plasma norepinephrine levels by more than $90 \%$ [24]. However, no clinical change as a result of these effects was observed in our study, primarily because of the decreased dose of propofol. Nonetheless, the effect on catecholamine levels may at least be a contributing factor to the changes in oxygenation and HPV.

The most important limitation of the study is the use of central venous instead of pulmonary arterial blood to measure the Qs/Qt. This may lead to bias, especially considering that dexmedetomidine can also affect myocardial oxygen consumption. Moreover, comparisons of cardiac output and pulmonary pressure would probably offer some further explanations of the findings. However, in several previous studies [12], including several with OLV [11] [13] [14], it has been shown that central venous blood sampling can be used to measure Qs/Qt and can be assumed to be reliable. In practice, pulmonary arterial catheters are associated with several complications, and they are very rarely used during thoracic surgery. Moreover, changes in Qs/QT were the secondary outcome, after oxygenation of the present study.

We conclude that intravenous administration of dexmedetomidine during OLV is associated with an improvement in oxygenation and a decrease in pulmonary shunt. There are several potentially complex mechanisms to explain this finding, including both sympatholytic and transient increase of pulmonary arterial pressures. Considering its other reported benefits, our results support recommending the use of dexmedetomidine during thoracic surgery.

\section{Declaration of Interests}

The authors have no conflicts of interest.

\section{Funding}

The authors used departmental funding only.

\section{References}

[1] Ishikawaa, S. and Lohsera, J. (2011) One-Lung Ventilation and Arterial Oxygenation. Current Opinion in Anesthesiology, 24, 24-31. http://dx.doi.org/10.1097/ACO.0b013e3283415659

[2] Rozé, H., Lafargue, M., Perez, P., Tafer, N., Batoz, H., Germain, C., Janvier, G., Ouattara, A., Karzai, W. and Schwarzkopf, K. (2012) Reducing Tidal Volume and Increasing Positive End-Expiratory Pressure with Constant Plateau Pressure during One-Lung Ventilation: Effect on Oxygenation. British Journal of Anaesthesia, 108, 1022-1027. http://dx.doi.org/10.1093/bja/aes090

[3] Lohser, J. (2008) Evidence-Based Management of One-Lung Ventilation. Anesthesiology Clinics, 26, 241-272. http://dx.doi.org/10.1016/j.anclin.2008.01.011

[4] Malhotra, R.K., Johnstone, C. and Banerjee, A. (2014) Dexmedetomidine in Peripheral and Neuraxial Block: A MetaAnalysis. British Journal of Anaesthesia, 112, 390-391. http://dx.doi.org/10.1093/bja/aet568

[5] Jakob, S.M., Ruokonen, E. and Takala, J. (2014) Efficacy of Dexmedetomidine Compared with Midazolam for Sedation in Adult Intensive Care Patients. British Journal of Anaesthesia, 112, 581-582. 
http://dx.doi.org/10.1093/bja/aeu032

[6] Elhakim, M., Abdelhamid, D., Abdelfattach, H., Magdy, H., Elsayed, A. and Elshafei, M. (2010) Effect of Epidural Dexmedetomidine on Intraoperative Awareness and Post-Operative Pain after One-Lung Ventilation. Acta Anaesthesiologica Scandinavica, 54, 703-709. http://dx.doi.org/10.1111/j.1399-6576.2009.02199.x

[7] Grewal, A. (2011) Dexmedetomidine: New Avenues. Journal of Anaesthesiology Clinical Pharmacology, 27, $297-302$. http://dx.doi.org/10.4103/0970-9185.83670

[8] Carollo, D.S., Nossaman, B.D. and Ramadhyani, U. (2008) Dexmedetomidine: A Review of Clinical Applications. Current Opinion in Anesthesiology, 21, 457-461. http://dx.doi.org/10.1097/aco.0b013e328305e3ef

[9] Lubbe, N., Bornscheuer, A. and Kirchner, E. (1991) The Effect of Clonidine on the Intrapulmonary Right-to-Left Shunt in One-Lung Ventilation in the Dog. Der Anaesthesist, 40, 391-396.

[10] Kernan, S., Rehman, S., Meyer, T., Bourbeau, J., Caron, N. and Tobias, J.D. (2011) Effects of Dexmedetomidine on Oxygenation during One-Lung Ventilation for Thoracic Surgery in Adults. Journal of Minimal Access Surgery, 7, 227-231. http://dx.doi.org/10.4103/0972-9941.85645

[11] Senturk, N.M., Dilek, A., Camci, E., Senturk, E., Orhan, M., Tuğrul, M. and Pembeci, K. (2005) Effects of Positive End-Expiratory Pressure on Ventilatory and Oxygenation Parameters during Pressure-Controlled One-Lung Ventilation. Journal of Cardiothoracic and Vascular Anesthesia, 19, 71-75. http://dx.doi.org/10.1053/j.jvca.2004.11.013

[12] Turnaoğlu, S., Tuğrul, M., Camci, E., Cakar, N., Akinci, O. and Ergin, P. (2001) Clinical Applicability of the Substitution of Mixed Venous Oxygen Saturation by Central Venous Saturation. Journal of Cardiothoracic and Vascular Anesthesia, 15, 574-580. http://dx.doi.org/10.1053/jcan.2001.26534

[13] Garutti, I., Quintana, B., Olmedilla, L., Cruz, A., Barranco, M. and Garcia de Lucas, E. (1999) Arterial Oxygenation during One-Lung Ventilation: Combined versus General Anaesthesia. Anesthesia \& Analgesia, 88, 494-499.

[14] Ozcan, P.E., Senturk, M., Sungur Ulke, Z., Toker, A., Dilege, S., Ozden, E. and Camci, E. (2007) Effects of Thoracic Epidural Anaesthesia on Pulmonary Venous Admixture and Oxygenation during One-Lung Ventilation. Acta Anaesthesiologica Scandinavica, 51, 1117-1224. http://dx.doi.org/10.1111/j.1399-6576.2007.01374.X

[15] Groh, J., Kuhnle, G.E., Ney, L., Sckell, A. and Goetz, A.E. (1995) Effects of Isoflurane on Regional Pulmonary Blood Flow during One-Lung Ventilation. British Journal of Anaesthesia, 74, 209-216. http://dx.doi.org/10.1093/bja/74.2.209

[16] Conacher, I.D. (2000) 2000-Time to Apply Occam’s Razor to Failure of Hypoxic Pulmonary Vasoconstriction during One-Lung Ventilation. British Journal of Anaesthesia, 84, 434-436. http://dx.doi.org/10.1093/oxfordjournals.bja.a013465

[17] Gurbet, A., Basagan-Mogol, E., Turker, G., Ugun, F., Kaya, F.N. and Ozcan, B. (2006) Intraoperative Infusion of Dexmedetomidine Reduces Perioperative Analgesic Requirements. Canadian Journal of Anesthesia, 53, 646-652. http://dx.doi.org/10.1007/BF03021622

[18] Silove, E.D. and Grover, R.F. (1968) Effects of Alpha Adrenergic Blockade and Tissue Catecholamine Depletion on Pulmonary Vascular Response to Hypoxia. Journal of Clinical Investigation, 47, 274-285. http://dx.doi.org/10.1172/JCI105724

[19] Schwarzkopf, K., Schreiber, T., Bauer, R., Schubert, H., Preussler, N.P., Gaser, E., Klein, U. and Karzai, W. (2001) The Effects of Increasing Concentrations of isoflurane and Desfluraneon Pulmonary Perfusion and Systemic Oxygenation during One-Lung Ventilation in Pigs. Anesthesia \& Analgesia, 93, 1434-1438. http://dx.doi.org/10.1097/00000539-200112000-00017

[20] Karzai, W., Haberstroh, J. and Priebe, H.J. (1998) Effects of Desflurane and Propofol on Arterial Oxygenation during One-Lung Ventilation in the Pig. Acta Anaesthesiologica Scandinavica, 42, 648-652. http://dx.doi.org/10.1111/j.1399-6576.1998.tb05296.x

[21] Ngwenyama, N.E., Anderson, J., Hoernschemeyer, D.G. and Tobias, J.D. (2008) Effects of Dexmedetomidine on Propofol and Remifentanil Infusion Rates during Total Intravenous Anesthesia for Spine Surgery in Adolescents. Pediatric Anesthesia, 18, 1190-1195.

[22] Taittonen, M.T., Kirvelä, O.A., Aantaa, R. and Kanto, J.H. (1997) Effect of Clonidine and Dexmedetomidine Premedication on Perioperative Oxygen Consumption and Haemodynamic State. British Journal of Anaesthesia, 78, 400406. http://dx.doi.org/10.1093/bja/78.4.400

[23] Kästner, S.B., Kull, S., Kutter, A.P., Boller, J., Bettschart-Wolfensberger, R. and Huhtinen, M.K. (2005) Cardiopulmonary Effects of Dexmedetomidine in Sevoflurane-Anesthetized Sheep with and without Nitric Oxide Inhalation. American Journal of Veterinary Research, 66, 1496-1502. http://dx.doi.org/10.2460/ajvr.2005.66.1496

[24] Kallio, A., Scheinin, M., Koulu, M., Ponkilainen, R., Ruskoaho, H., Viinamäki, O. and Scheinin, H. (1989) Effects of Dexmedetomidine, a Selective Alpha 2-Adrenoceptor Agonist, on Hemodynamic Control Mechanisms. Clinical Pharmacology and Therapeutics, 46, 33-42. http://dx.doi.org/10.1038/clpt.1989.103 